\title{
Watermelon Juice: Potential Functional Drink for Sore Muscle Relief in Athletes
}

\author{
Martha P. Tarazona-Díaz, ${ }^{\dagger \neq}$ Fernando Alacid, ${ }^{\S}$ María Carrasco, ${ }^{\S}$ Ignacio Martínez, \\ and Encarna Aguayo $*, \dagger, \ddagger$
}

\footnotetext{
${ }^{\dagger}$ Department of Food Engineering, Universidad Politécnica de Cartagena, Paseo Alfonso XIII 48, E-30203 Cartagena, Murcia, Spain

${ }^{\ddagger}$ Institute of Plant Biotechnology, Universidad Politécnica de Cartagena, Plaza del Hospital s/n, Campus Muralla del Mar, 30202 Cartagena, Murcia, Spain

${ }^{\S}$ Faculty of Physical Activity and Sport Sciences, Catholic University of San Antonio Campus de los Jerónimos s/n, 30107 Guadalupe, Murcia, Spain

${ }^{\#}$ Faculty of Medicine at the University of Murcia, Campus of San Javier, 30720 Santiago de la Ribera, San Javier, Murcia, Spain
}

ABSTRACT: L-Citrulline is an excellent candidate to reduce muscle soreness, and watermelon is a fruit rich in this amino acid. This study investigated the potential of watermelon juice as a functional drink for athletes. An in vitro study of intestinal absorption of L-citrulline in Caco-2 cells was performed using unpasteurized (NW), pasteurized $\left(80{ }^{\circ} \mathrm{C}\right.$ for $\left.40 \mathrm{~s}\right)$ watermelon juice (PW) and, as control, a standard of L-citrulline. L-citrulline bioavailability was greater when it was contained in a matrix of watermelon and when no heat treatment was applied. In the in vivo experiment (maximum effort test in a cycloergometer), seven athletes were supplied with $500 \mathrm{~mL}$ of natural watermelon juice (1.17 g of L-citrulline), enriched watermelon juice ( $4.83 \mathrm{~g}$ of $\mathrm{L}$ citrulline plus $1.17 \mathrm{~g}$ from watermelon), and placebo. Both watermelon juices helped to reduce the recovery heart rate and muscle soreness after $24 \mathrm{~h}$.

KEYWORDS: L-citrulline, bioavailability, cellular transport, anaerobic performance, Caco-2 cell, pasteurization, cellular absorption

\section{INTRODUCTION}

Until recently, L-citrulline attracted little interest among the nutrition community, almost certainly because it is a nonprotein amino acid and was viewed solely as a metabolic intermediary in the urea cycle. Also, L-citrulline is almost absent from natural foods, watermelon being a notable exception. ${ }^{1}$ The elevated content of L-citrulline, a major hydroxyl radical scavenger, allows wild watermelon to resist drought-mediated oxidative stress in harsh environments. ${ }^{2}$ These antioxidant properties, together with the ability to generate nitric oxide (NO), make citrulline an excellent candidate for the treatment of pathological situations characterized by oxidative stress and decreased arginine availability, ${ }^{3}$ for example, hypertension, heart failure, atherosclerosis, sickle cell disease, ${ }^{4-6}$ and sexual stamina and erectile functions. ${ }^{7}$ Other benefits associated with L-citrulline intake include improving athletic performance due to NO synthesis and increasing glucose transport in skeletal muscle. ${ }^{8}$ Citrulline malate was shown to increase levels of arginine and ornithine (which are important for muscle growth) and influence levels of growth hormone. ${ }^{9}$ For example, in aged rats, 1 week refeeding with an L-citrulline-enriched diet (at $5 \mathrm{~g} / \mathrm{kg}$ day) induced an increase in absolute muscle protein synthesis rate together with an increase in protein. ${ }^{10}$ A dietary supplement rich in L-citrulline also helps in smooth muscle relaxation. ${ }^{11}$ Pérez-Guisado and Jakeman ${ }^{12}$ found that citrulline malate $(8 \mathrm{~g} /$ day $)$ enhances athletic anaerobic performance and relieves muscle soreness. L-Citrulline also accelerates lactic acid removal, allowing better physical performance, that is, more intense training and faster recovery after each workout. ${ }^{13}$
Today, the food industry is researching natural source foods, and their enrichment with bioactive compounds, as substitutes of pharmacological products. Watermelon juice, naturally rich in L-citrulline, is an excellent option for athletes who want to improve their sports performance. However, a prerequisite for this juice should be the adequate bioavailability of L-citrulline in the juice composition and after thermal pasteurization. Methods for assessing the bioavailability include in vitro models such as the Caco-2 Cell prediction of intestinal absorption, which has been adapted to test a number of foods. $^{14}$

The aim of the present study was to determine the in vitro $\mathrm{L}$ citrulline bioavailability from a synthetic standard or natural watermelon juice (pasteurized or not) and, according to these results, determine the effect of a potential functional watermelon juice in an in vivo experiment in athletic performance using a test of maximum effort cycle ergometer.

\section{MATERIALS AND METHODS}

In Vitro Study in Pasteurized or Nonpasteurized Watermelon Juice Enriched with L-Citrulline. Reagents. Dulbecco's modified Eagle's medium (DMEM), nonessential amino acids (NEAA), fetal bovine serum, and antibiotic solution (penicillin and streptomycin) were obtained from GIBCO (Eggenstein, Germany). Sodium pyruvate trypsin solution-EDTA, Hank's salts with $\mathrm{Ca}^{2+}$ but not $\mathrm{Mg}^{2+}$ (HBSS), and Hank's salts without phenol red were

Received: March 11, 2013

Revised: July 16, 2013

Accepted: July 17, 2013 
purchased from Sigma (Madrid, Spain). L-Citrulline was purchased from Acofarma (Barcelona, Spain). Caco-2 cells (HTB-37) were obtained from the American Type Culture Collection (ATCC, Manassas, VA, USA). The Caco-2 cell line derives from a human colon adenocarcinoma, which has morphological and functional similarities to human intestinal epithelial cells. These cells were stored in a bank of cell cultures frozen in liquid nitrogen.

Watermelon Juice Preparation. Ten seedless watermelons (Citrullus lanatus cv. 'Motril') were purchased at commercial maturity from a local supermarket (Cartagena, Spain). The fruits were transported $(300 \mathrm{~m})$ to the laboratory and stored at $10{ }^{\circ} \mathrm{C}$ after washing with $100 \mathrm{mg} \mathrm{L}^{-1}$ sodium hypochlorite and drying using absorbent paper. Pulp was liquefied (Moulinex FruttiPro-BKA1, Spain) and transferred to a sterile container. This juice was unpasteurized natural watermelon (NW treatment) or was pasteurized at $80{ }^{\circ} \mathrm{C}$ for $40 \mathrm{~s}$ and immediately cooled on ice to $8{ }^{\circ} \mathrm{C}$ (pasteurized watermelon (PW) treatment) using a thermoresistometer (Mastia, Cartagena, Spain). The pasteurization temperature and time were chosen on the basis of preliminary data for obtaining optimal quality in red color, lycopene, antioxidant, and phenolic content of the watermelon juice. ${ }^{15}$ Juices were transferred to sterile glass containers and stored at $4{ }^{\circ} \mathrm{C}$ until analysis ( 3 days later). A standard of $\mathrm{L}$ citrulline dissolved in Milli- $Q$ water was used as a control.

Cell Culture. Caco- 2 cells were extracted from the nitrogen tank and introduced into a bath at $37{ }^{\circ} \mathrm{C}$ to accelerate thawing. Cells were transferred to a $25 \mathrm{~cm}^{2}$ flask with DMEM and incubated in a controlled atmosphere at $37{ }^{\circ} \mathrm{C}, 5 \% \mathrm{CO}_{2}$, and $95 \%$ relative humidity (RH) for 21 days, until the cells reached an optimum level of differentiation. ${ }^{16}$ Cells adhered to the flask and grew until they covered the surface, forming a cell monolayer, and the medium was changed every 2-3 days with DMEM. When the cells reached confluence, they proceeded to trypsinization and dilution of cell suspension. Trypsinization was done to dislodge the cells and transfer to larger surfaces, using proteolytic agents such as trypsin. For the dilution of the cell suspension, the cells were diluted in DMEM to a concentration of $5 \times 10^{5}$ cells $\mathrm{cm}^{-2}$. For absorption studies, cells were seeded on polycarbonate inserts (Costar Transwell plate inserts, $12 \mathrm{~mm}$ polycarbonate, pore diameter $=0.3 \mathrm{~mm}$; Costar, Tewksbury, MA, USA).

Measurement of Transepithelial Electrical Resistance (TEER). Evaluations of epithelial integrity and maturity of the monolayers were performed by measuring TEER. This was measured using a voltmeter with an EndOhm-12 chamber (EVOM, World Precision Instruments, Berlin, Germany). Values are expressed in standard units of ohms per square centimeter and presented as the mean of triplicate measurements. For calculation, the equation TEER $=R_{\text {total }} \times A$ was used $\left(R_{\text {total }}\right.$ is the measured resistance in ohms and $A$ is the surface area in $\left.\mathrm{cm}^{2}\right)$.

Absorption of L-Citrulline in Caco-2 Cells, Absorption Speed, and Apparent Permeability. Transport assay was performed by incubating an aliquot of each sample $(0.2 \mathrm{~mL})$ in the apical part of the polycarbonate insert. All samples were prepared to obtain a concentration of $0.685 \mathrm{mM}$ of L-citrulline. This concentration was similar to kinetic parameters of citrulline uptake $\left(K_{\mathrm{m}}\right.$ the MichaelisMenten constant) ${ }^{17}$ allowing work in nonsaturable intervals and knowledge of the difference among treatments. At 4, 8, and $15 \mathrm{~min}$ cellular transport was performed in triplicate; these times were used according to Bahri et al., ${ }^{17}$ who reported that absorption at $37^{\circ} \mathrm{C}$ is linear up to $12 \mathrm{~min}$. After incubation $\left(37^{\circ} \mathrm{C}, 5 \% \mathrm{CO}_{2}, 95 \% \mathrm{RH}\right)$, the amount of $\mathrm{L}$-citrulline remaining in the apical portion was determined by HPLC-MS. ${ }^{1}$ Absorption was calculated by comparing initial and final citrulline contents (after cell transport), and absorption speed was determined as the amount of citrulline (ng) through the polycarbonate insert per second.

The permeability coefficient $\left(P_{\text {app }}\right)$ across Caco- 2 cell monolayers was calculated using the following equation: $P_{\text {app }}(\mathrm{cm} / \mathrm{s})=(\mathrm{d} Q / \mathrm{d} t)(1 /$ $\left.A C_{0}\right)$, where $P_{\text {app }}$ is the apparent permeability coefficient $(\mathrm{cm} / \mathrm{s}), \mathrm{d} Q /$ $\mathrm{d} t$ is the rate of transport of $\mathrm{L}$-citrulline $\left(\mu \mathrm{g} \mathrm{s}^{-1}\right), A$ is the monolayer growth surface area $\left(\mathrm{cm}^{2}\right)$, and $C_{0}$ is the initial concentration the $\mathrm{L}$ citrulline in the donor side $\left(\mu \mathrm{g} \mathrm{mL}^{-1}\right) .{ }^{18}$
In Vivo Study (Athletic Performance). Subjects. Students of Sport Sciences at the University of Murcia (7 men, mean \pm SD age, $22.7 \pm 0.8$ years; body mass, $68.9 \pm 3.8 \mathrm{~kg}$; height $=170.8 \pm 3.6 \mathrm{~cm}$; body mass index, $24.0 \pm 0.6 \mathrm{~kg} \mathrm{~m}^{-2}$ ) volunteered to participate in this investigation. The subjects were not competitive athletes, but they participated regularly in different sports. The study was approved by the Ethical Committee of the University of Murcia (Spain). All details of the study were explained to the participants, who also gave their written consent. Subjects completed a questionnaire about their personal history of cardiovascular diseases. Cardiopulmonary auscultation and resting blood pressure (Stethoscope, Quirumed S.L, Madrid, Spain) were assessed. Also, a baseline electrocardiogram (BTL-08 SD6 model, Columbia, USA) and spirometry at rest (Spiro analyzer ST-250R, Fukuda, Madrid, Spain) were performed. Furthermore, an anthropometric evaluation was performed according to the International Society for the Advancement of Kinanthropometry (ISAK). ${ }^{19}$ These determinations were performed on volunteers to determine inclusion or exclusion criteria, each subject undergoing a medical examination. All of these parameters were normal in all seven subjects, who were not taking any medication or suffering from injuries that could interfere with athletic performance.

Study Design. On the day prior to the completion of the test, participants did not practice any vigorous physical exercise or consume alcoholic beverages or stimulants. In addition, subjects were required to ingest a diet rich in carbohydrates at least $3 \mathrm{~h}$ before the start of testing. As Mandel et al. ${ }^{20}$ recommended, subjects ingested $500 \mathrm{~mL}$ of beverage $1 \mathrm{~h}$ before the test. Unpasteurized drinks were composed of (1) natural watermelon juice (NW) containing $1.17 \mathrm{~g}$ of citrulline from the proper watermelon, (2) enriched watermelon juice (EW) (6 $\mathrm{g} / 500 \mathrm{~mL}=1.17 \mathrm{~g}$ citrulline from watermelon $+4.83 \mathrm{~g}$ of citrulline added), and (3) sample placebo (infusion of fruit-flavored plants composed of rosehip, hibiscus, rooibos, apple pulp, natural flavors, and strawberry pieces. Placebo samples had a color similar to watermelon juice and $5.8 \mathrm{~g} / 100 \mathrm{~mL}$ of sugar, equivalent to total sugars, sucrose, glucose, and fructose, obtained by HPLC for watermelon juice. There is no recommendation for citrulline intake, but a dose of 6 or $8 \mathrm{~g}$ of citrulline malate has been used by other authors. ${ }^{9,12}$ The composition of each treatment is reported in Table 1. To minimize any expectancy effects, participants were not informed of the potential role of the different treatments on outcomes.

Table 1. Physicochemical Characteristics and L-Citrulline Content $^{a}$

\begin{tabular}{llll} 
& \multicolumn{1}{c}{ NW } & \multicolumn{1}{c}{ EW } & placebo \\
sugar content $(\%)$ & $5.80 \pm 0.03$ & $5.80 \pm 0.00$ & $5.80 \pm 0.06$ \\
density $(\mathrm{g} / \mathrm{mL})$ & $1.03 \pm 0.00$ & $1.03 \pm 0.01$ & $1.02 \pm 0.01$ \\
$L$ & $28.01 \pm 0.10$ & $24.20 \pm 0.09$ & $21.85 \pm 0.02$ \\
${ }^{\circ}$ hue & $37.42 \pm 0.03$ & $37.21 \pm 0.04$ & $34.47 \pm 0.06$ \\
chroma & $15.94 \pm 0.01$ & $16.75 \pm 0.09$ & $11.04 \pm 0.00$ \\
citrulline $(\mathrm{g} / \mathrm{L})$ & $2.33 \pm 0.13$ & $12.33 \pm 0.18$ &
\end{tabular}

${ }^{a}$ Values are means $(n=3) \pm$ SE. NW (natural unpasteurized watermelon juice), EW (enriched unpasteurized watermelon juice). Sugars contents $=$ sum of glucose, fructose, and sucrose. Luminosity (CIE $\left.L^{*}\right)$, hue angle $\left({ }^{\circ} h=\tan ^{-1}\left(b^{*} / a^{*}\right)\right)$, chroma $=\left[\left(a^{*}\right)^{2}+\right.$ $\left.\left(b^{*}\right)^{2}\right]^{1 / 2}$.

The effect of each drink was tested on each test subject, with a separation of 5 days between each test. Allocation of drink order was randomized for each subject. For each test, participants were fitted with a chest strap and heart rate monitor (Monark, CR 2032, Taiwan), and each repetition was monitored. The exercise protocol commenced with a standardized 5 min warmup on a cycle ergometer at $75 \mathrm{~W}$ (Ergoline GmbH, Bitz, Germany). Participants completed 11 min for each test on a cycle ergometer (Monark, 874 E, Vansbro, Sweden) at a resistance of 4.5 and $5 \mathrm{~kg}$ depending on the subject's weight. That involved completing eight repetitions of $30 \mathrm{~s}$ exercise intervals, separated by $1 \mathrm{~min}$ of rest and a final $3 \mathrm{~min}$ recovery. This protocol of 
alternating intense physical activity followed by a short break was obtained from Pérez-Guisado and Jakeman, ${ }^{12}$ as citrulline malate supplementation would be less effective in enhancing the performance of short aerobic exercises sessions or anaerobic sessions with sufficient rest.

During resistance exercise intervals, blood lactate samples were taken at $0,2,4,6,8$, and 3 min of recovery. Blood samples were drawn by puncture (on the ring finger of the left-hand) using a sterile lancet (Dr. Lange, Warsaw, Poland) and dispensed into collection capillaries of $0.01 \mathrm{~mL}$ (Dr. Lange, Warsaw, Poland). Immediately, blood samples were transferred into cuvettes (LKM 140, Dr. Lange Cuvette Test, Berlin, Germany), containing anticoagulant, for the immediate determination of lactate concentrations using an automated analyzer (Miniphotometer $8 / 8$ plus, LP 20, Dr. Lange, Berlin, Germany).

After each cycle ( 8 per test), ratings of perceived exertion were assessed using the Borg scale (6-20). ${ }^{21}$ After the end of each session (NW juice, EW juice, and placebo), the subjects self-reported their soreness 24 and $48 \mathrm{~h}$ after the physical exertion on a scale from 1 to 5 as follows: 1 , no soreness; 2 , minimal soreness with no impact on immediate training; 3 , medium soreness with minimal impact on immediate training; 4, high soreness with negative impact on immediate training; 5, maximum soreness with physical disability for immediate training. ${ }^{12}$

Statistical Analyses. The distribution of data in the in vivo experiment was initially assessed by the normality test of ShapiroWilk. Statistical analysis was performed using the nonparametric test. In both experiments, to compare the values obtained with each of the substances supplied, respective Friedman ANOVA was performed. Statistical analyses were performed with SPSS for Windows version 15.0. Data are presented as the mean \pm standard error. Statistical significance was set at $p<0.05$.

\section{RESULTS AND DISCUSSION}

Intestinal Absorption in Caco-2 Cells. Influence of the Monolayer in the Transepithelial Electrical Resistance. Minor differences were observed in the TEER values (data not shown), most probably due to the small variability of the monolayers noted by Brown et al. ${ }^{22}$ The established culture conditions allowed development of viable cell monolayers, uniform, differentiated, and functional, that is, with selective permeability. The measured values of TEER (data not shown), greater than $450 \mathrm{~cm}^{2}$, were within the ranges used by Lentz et al. $^{23}$ and Yamashita et al. ${ }^{24}$ The TEER across Caco- 2 cells increases with culture time, reaching a maximum after about 10-15 days, but full formation of transport systems requires 21-24 days. ${ }^{25}$ In this study Caco-2 cells were incubated for 21 days until the cells reached an optimum level of differentiation.

Absorption Percentage of L-Citrulline in Caco-2 Cells. Figure 1 shows the Caco-2 absorption of L-citrulline from NW and $\mathrm{PW}$ juices and control (L-citruille + water). Absorption percentage was statistically significant for the studied treatments, with NW juice attaining the highest absorption percentage $(18.87 \%)$ at $8 \mathrm{~min}$, being at that time significantly different from the other two treatments. For the PW juice and the control, the highest absorptions of L-citrulline were obtained in the first $4 \mathrm{~min}$ ( 13.19 and $11.85 \%$, respectively). These results show two interesting facts. First, the absorption of L-citrulline in the NW juice was greater than in the control. This indicates that the watermelon juice is a more suitable vehicle for the transport and bioavailability of L-citrulline than a pure standard, that is, a pharmacological formulation. Second, comparison of the absorption obtained for NW and PW juice showed that the application of heat treatment as pasteurization $\left(80{ }^{\circ} \mathrm{C} / 40 \mathrm{~s}\right)$ decreased the absorption percentage of $\mathrm{L}$ citrulline content in the same food matrix.

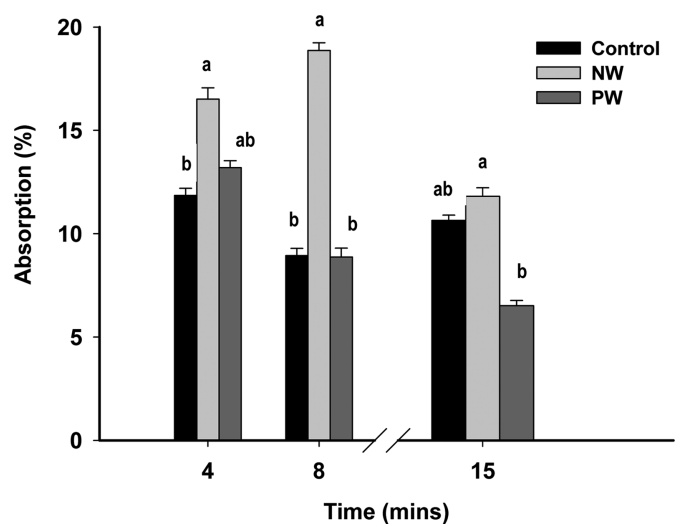

Figure 1. Absorption of L-citrulline from watermelon juice by Caco-2 cells. Values are means $(n=3 \pm \mathrm{SE})$. Control (L-citrulline); NW, unpasteurized natural watermelon juice; $\mathrm{PW}$, pasteurized watermelon juice. The same letter at each time point indicates no statistical difference according to the LSD test $p \leq 0.05$.

The relationship between processing treatment and bioavailability depends on each bioactive compound and food matrix. ${ }^{26}$ For example, heat treatment $\left(90{ }^{\circ} \mathrm{C} / 30 \mathrm{~s}\right)$ produced a significant decrease in tocopherol and carotenoid bioaccessibility in all three different beverages and increased the bioavailability of ascorbic acid. ${ }^{27}$ However, in amino acids such as L-citrulline, heat treatment could react with other compounds present in the watermelon juice (such as sugars) to form nutritionally unavailable derivatives, the most common examples of which are Maillard products, reducing the absorption percentage. A similar response has been reported in lysine: when a processed food or feedstuff is subjected to heating, the lysine present can be altered to nutritionally unavailable derivatives. ${ }^{28,29}$ Van Barneveld et al. ${ }^{30}$ found a $73 \%$ decrease in the available lysine content of field peas heated from 110 to $165^{\circ} \mathrm{C}$ when determined using an animal growth assay. In our case, $32 \%$ of the previously available L-citrulline was not absorbed in the pasteurized juice.

Absorption percentages found in this work for citrulline in the watermelon juice $(13.19-18.87 \%)$ were lower than those found in the bioavailability of trans- $\beta$-carotene in cassava (23.85\%) and sweet potato (25.82\%) but similar to that in beans $(32.33 \%){ }^{31}$ Actually, the bioaccessibility of carotenoids from main dietary sources was highly variable, ranging from $<0.1 \%$ ( $\beta$-carotene from raw tomato) to almost $100 \%(\alpha$ tocopherol from white bread). ${ }^{32}$ The bioaccessibility of carotenoids has been also studied in watermelon using an in vitro model, ${ }^{33}$ obtaining $2.7 \%$ for lycopene, $30.2 \%$ for $\beta$ carotene, and $64.3 \%$ for phytoene. These previous results show the importance of considering influential factors such as the type of bioactive compound, food matrix, food processing, and isomerization in the bioavailability results. ${ }^{32}$ However, it is important to remember that although in vitro models approximate the bioavailability of functional compounds, the actual in vivo cell reality is different.

Absorption Speed. An important parameter to know in bioavailability studies is the absorption speed of the compound. Faster absorption during the first minute avoids competition with other compounds and enhances any beneficial effects of the functional compound concerned. Figure 2 shows the absorption speed of L-citrulline in Caco-2 from watermelon juice. Juice preparations were statistically different at each time point. In all cases, NW juice was absorbed more quickly than 


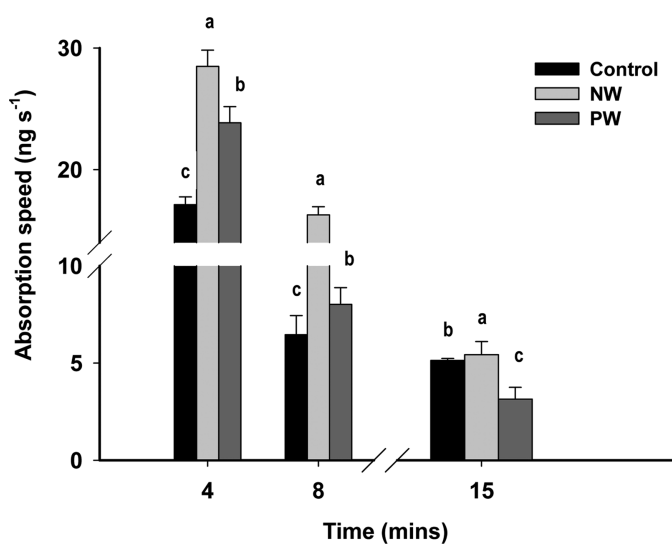

Figure 2. Absorption speed of L-citrulline from watermelon juice in Caco- 2 cells. Values are means $(n=3 \pm \mathrm{SE})$. Control, L-citrulline; NW, unpasteurized natural watermelon juice; PW, pasteurized watermelon juice. The same letter at each time point indicates no statistical difference according to the LSD test at $p \leq 0.05$.

the standard or PW juice. In all samples, the absorption speed decreased with time at $15 \mathrm{~min}$ of cellular transport, and there was a greater reduction. This shows that L-citrulline bioavailability may be limited by its intestinal absorption. This reduction in the absorption speed could be explained by the nonlinearity absorption at that time. ${ }^{17}$

Apparent Permeability. Permeability values of the analyzed samples are shown in Figure 3. Samples tested showed

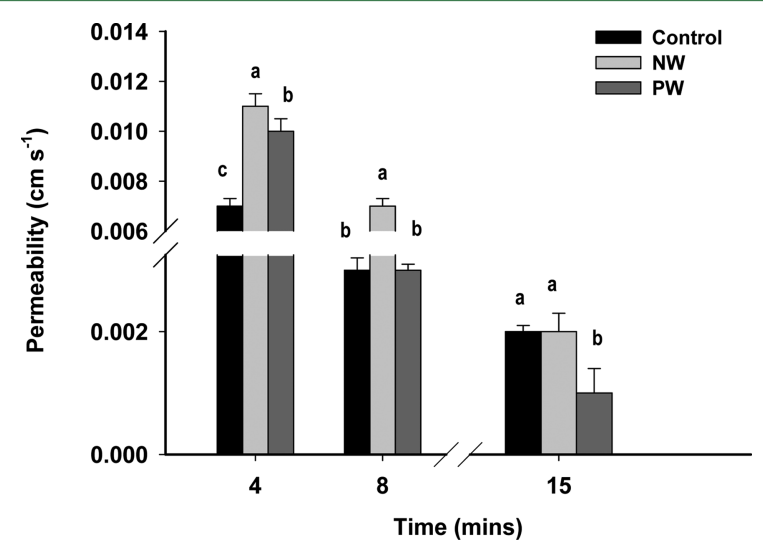

Figure 3. Permeability $\left(P_{\mathrm{app}}, \mathrm{cm} / \mathrm{s}\right)$ of L-citrulline from functional watermelon juice in Caco- 2 cells. Values are means $(n=3 \pm \mathrm{SE})$. Control, L-citrulline; NW, unpasteurized natural watermelon juice; $\mathrm{PW}$, pasteurized watermelon juice. The same letter at each time point indicates no statistical difference according to the LSD test at $p \leq 0.05$.

significant differences, with citrulline present in the NW juice showing higher permeation of cells compared to the PW juice and standard. All treatments showed reduced permeability over time. Reductions of $40.90 \%$ in the 8 th minute and $80 \%$ in the 15 th minute were obtained for the NW juice.

Some authors prefer to use the permeability coefficient $\left(P_{\text {app }}\right)$ instead of the absorption speed to quantify the absorption process in situ in animal models, because absorption speed does not encompass the surface of useful absorption, which varies in the different areas of the gastrointestinal tract that are being tested. $^{34}$ However, in this study, absorption speed and permeability presented similar behaviors. Absorption (\%), absorption speed, and permeability of Caco-2 cells were higher when the L-citrulline was supplied as a NW juice. The pasteurization treatment affected the percentage, speed, and permeability of absorption.

In Vivo Study (Athletic Performance). Pedaling Test. According to the results shown in Figure 4, each subject had a

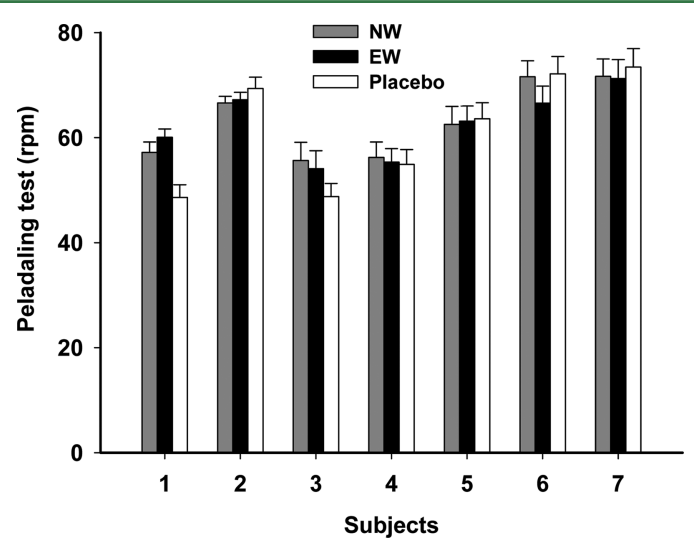

Figure 4. Pedaling test on a cycle ergometer in revolutions per minute $(\mathrm{rpm})$. Values are mean $(n=48 \pm \mathrm{SE}, 8$ cycles of $30 \mathrm{~s}$ each and 6 measurements were performed every $5 \mathrm{~s}$ ). NW, unpasteurized natural watermelon juice; EW, enriched unpasteurized watermelon juice. No significant differences were found between tests for each of the substances supplied.

constant and particular frequency throughout the pedaling test. Revolutions per minute (rpm) were between 48 and 73 . According to Lucía et al. ${ }^{35}$ trained cyclists generally pedal at 90-100 rpm, and this high pedaling cadence (>80 rpm) causes less muscle fatigue. ${ }^{36}$ However, the cadence is more efficient at speeds of 50-60 rpm. ${ }^{37}$ Participants were students of sport sciences, but not trained cyclists. Therefore, the speeds reached during the test were less than those of professional cyclists. However, the main objective was to determine athletic performance after ingestion of each substance. No significant differences were observed when the rpm and intake of different drinks were compared, although two subjects ( 1 and 3 ) with a lower placebo pedaling speed had slightly increased speeds with the watermelon juices. This could show that citrulline is more efficient in those people who practice moderate physical activity than in professional atheletes.

Heart Rate. Figure 5 shows the heart rate of subjects at the beginning and end of the test and for 1 and $3 \mathrm{~min}$ of recovery. Mean heart rates throughout the experimental protocol followed a similar pattern across trials, independent of beverage. The initial average heart rate was 106 beats per $\mathrm{min}(\mathrm{bpm})$ and increased to $170 \mathrm{bpm}$ during exercise. After 1 and $3 \mathrm{~min}$ of recovery, the rate decreased to 148 and $138 \mathrm{bpm}$. Although no significant difference was found, a trend of greater heart rate reduction after 1 and 3 min of recovery was observed when natural or enriched watermelon juices were ingested.

Perceived Exertion and Muscle Soreness. Perceived exertion was focused on "what" the individual was feeling during exercise, using the Borg scale. Mean perceived exertion was between 18.75 and 19.33 (Figure 6). These values denote a maximal exercise test on a cycle ergometer, as 20 is the maximum value on the scale for perceived exertion. No differences in ratings of perceived exertion were observed in each test or between beverages provided. This indicates that the effort for the subjects was the same in all tests regardless of the beverage ingested. 


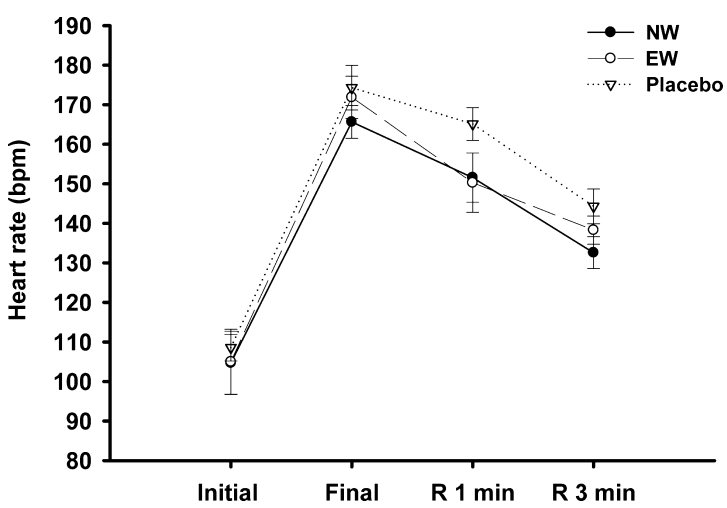

Figure 5. Heart rate in beats per minute (bpm), at the start (initial) and at the end of physical effort (final) and after 1 and 3 min of recovery (R 1 and R 3). NW, unpasteurized natural watermelon juice; EW, enriched unpasteurized watermelon juice. Values are mean $(n=7$ \pm SE subjects). No significant differences were found between tests for each of the substances supplied.

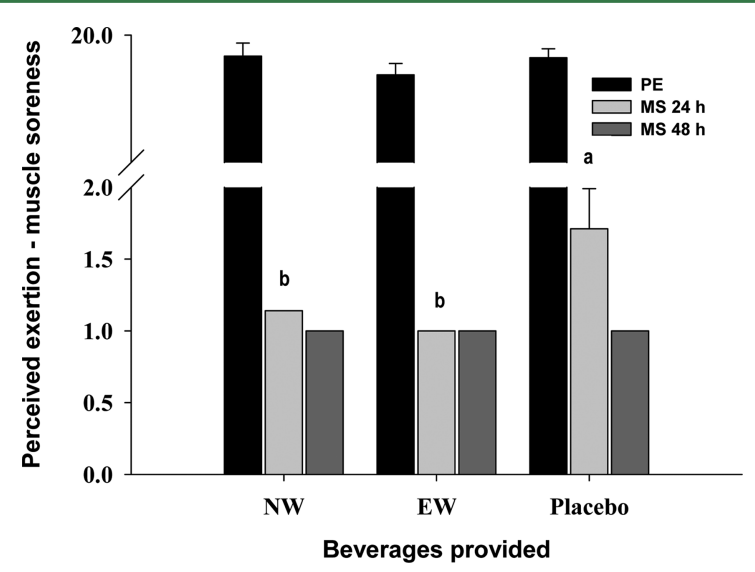

Figure 6. Perceived exertion (PE, scale of 6-20) and muscle soreness (MS, scale 1-5) after 24 and $48 \mathrm{~h}$ of performed exercise tests according to beverage. NW, unpasteurized natural watermelon juice; EW, enriched unpasteurized watermelon juice. Values are mean $(n=7$ subjects $\pm \mathrm{SE}$ ). The analysis of variance showed significant differences only in MS $24 \mathrm{~h}$. The same letter at each time indicates no statistical difference according to the LSD test at $p \leq 0.05$.

Muscle soreness after $24 \mathrm{~h}$ of exercise was significantly greater when placebo was supplied. This indicates that subjects felt more muscle soreness when they performed physical exercise with placebo than with either watermelon juice. However, NW and EW juice did not differ from each other, indicating that $1.17 \mathrm{~g}$ of $\mathrm{L}$-citrulline was sufficient amino acid to help to reduce the physical soreness. After $48 \mathrm{~h}$, the muscle soreness was reduced to 1 in all treatments, even in placebo drinks, with no significant differences. These results partially agree with those reported by Perez-Guisado and Jakeman, ${ }^{12}$ where citrulline malate supplementation $(8 \mathrm{~g})$ reduced muscle soreness 24 and even $48 \mathrm{~h}$ anaerobic postexercise.

Some studies have found that supplementation of citrulline reduces fatigue, stimulates hepatic ureogenesis, and promotes the renal reabsorption of bicarbonates. ${ }^{38}$ These metabolic actions have a protective effect against acidosis and ammonia poisoning, explaining the antifatigue properties of citrulline malate. Bendahan et al. ${ }^{39}$ demonstrated that citrulline malate ingestion reduces the sensation of fatigue, increases the rate of oxidative ATP production during exercise by $34 \%$, and increases the rate of phosphocreatine recovery after exercise by $20 \%$, indicating a larger contribution of oxidative ATP synthesis to energy production. According to our results, supplying watermelon juice enriched or not in L-citrulline significantly reduced muscular soreness $24 \mathrm{~h}$ after exercise when compared with placebo. Takeda et al. ${ }^{40}$ indicated that citrulline supplementation prolongs the period until exhaustion in swimming exercise and that this effect involves inhibition of blood ammonia accumulation when the intensity of exercise is comparable to maximal lactate steady state. These authors suggest that citrulline suplementation would be very helpful for individuals performing high-intensity exercise.

Blood Lactate Concentration. Blood lactate levels (data not shown) before starting an intensive activity were in the normal range for blood lactate, from 0.5 to $2.2 \mathrm{mmol} / \mathrm{L},{ }^{41}$ with no statistical differences between treatments. Blood lactate concentrations were slightly elevated from basal levels with the onset of exercise, increasing to $14.43 \mathrm{mmol} / \mathrm{L}$ after 2 min of exercise, values similar to those reported by Leicht et al., ${ }^{42}$ who obtained a lactate concentration of $14.8 \pm 2.9 \mathrm{mmol} / \mathrm{L}$ in anaerobic test with a bicycle ergometer for $30 \mathrm{~s}$. Concentrations increased after $4 \mathrm{~min}$ for the three treatments $(17.40 \mathrm{mmol} / \mathrm{L})$ and gradually decreased following recovery, regardless of the beverage ingested. According to these results blood lactate concentration is associated with an increase in exercise intensity, and this agrees with other published works. ${ }^{43}$

In this experiment, no significant differences were observed between the drinks supplied and blood lactate concentration obtained. Although bood lactate concentration is an indicator of the intensity of anaerobic work done, ${ }^{44}$ there are arguments over its suitability as lactic acid accumulates in nonactive muscles during exercise $\mathrm{e}^{45}$ and muscle fatigue is due to an increase in hydrogen ions (lower $\mathrm{pH}$ ) in the muscle tissue, not the lactate itself. ${ }^{43,46}$ Citrulline is not thought to regulate $\mathrm{pH}$, so it is not surprising that no differences were found in this experiment. However, authors have found that supplementation with this amino acid helps improve athletic performance and achieve faster recovery. ${ }^{9,38,39}$ Giannesini et al. ${ }^{47}$ demonstrated that citrulline malate supplementation in healthy rats has an ergogenic effect associated with an improvement of muscular contraction efficiency.

In conclusion, this paper demonstrates the possible "functionality" of watermelon juice rich in natural L-citrulline. The in vitro study showed a greater L-citrulline bioavailability when contained in a natural matrix such as nonpasteurized watermelon juice, and this juice, enriched or not in L-citrulline, helped to reduce muscle soreness. Future research should be focused on the minimal concentrations of citrulline required for reduction of muscle fatigue and other health benefits in stress, athletic performance, and cardiovascular disease. This amino acid could be supplied as watermelon juice or as products enriched in citrulline from watermelon extraction. In both case, it is important to choose watermelon cultivars rich in this amino acid. Functional compound contents in fruits and vegetables play a key role in the design of new natural and functional products (beverages, juices, energy bars, etc.) by the food industry instead of synthetic compounds from pharmaceutical industry.

\section{AUTHOR INFORMATION}

\section{Corresponding Author}

*(E.A.) Phone: 00-34-968325750. Fax: 00-34-96832543. Email: encarna.aguayo@upct.es. 


\section{Funding}

This work has been made possible by Universidad Politécnica de Cartagena.

Notes

The authors declare no competing financial interest.

\section{REFERENCES}

(1) Tarazona-Díaz, M.; Viegas, J.; Moldao-Martins, M.; Aguayo, E. Bio-active compounds from flesh and by-product of Spanish fresh-cut watermelons cultivars. J. Sci. Food Agric. 2011, 91, 805-812.

(2) Akashi, K.; Miyake, C.; Yokota, A. Citrulline, a novel compatible solute in drought tolerant wild watermelon leaves, is an efficient hydroxyl radical scavenger. FEBS Lett. 2001, 508, 438-442.

(3) Bansal, V.; Rodriguez, P.; Wu, G.; Eichler, D. C.; Zabaleta, J.; Taheri, F.; Ochoa, J. B. Citrulline can preserve proliferation and prevent the loss of $\mathrm{CD} 3$ zeta chain under conditions of low arginine. JPEN, J. Parenter. Enteral Nutr. 2004, 28, 423-430.

(4) Ikeda, Y.; Young, L. H.; Scalia, R.; Lefer, A. M. Cardioprotective effects of citrulline in ischemia/reperfusion injury via a non-nitric oxide-mediated mechanism. Methods Find Exp. Clin. Pharmacol. 2000, 22, 563-571.

(5) Romero, M. J.; Platt, D. H.; Caldwell, R. B.; Caldwell, R. W. Therapeutic use of citrulline in cardiovascular disease. Cardiovasc. Drug Rev. 2006, 24, 275-290.

(6) Figueroa, A.; Sánchez-Gonzales, M. A; Perkins-Veazie, P. M.; Arjmandi, B. H. Effects of watermelon supplementation on aortic blood pressure and wave reflection in individuals with prehypertension: a pilot study. Am. J. Hypertens. 2011, 24, 40-44.

(7) Drewes, S. E.; George, J.; Khan, F. Recent findings on natural products with erectile-dysfunction activity. Phytochemistry 2003, 62, 1019-1025.

(8) Balon, T. W.; Nadler, J. L. Evidence that nitric oxide increases glucose transport in skeletal muscle. J. Appl. Physiol. 1997, 82, 359363.

(9) Sureda, A.; Córdoba, A.; Ferrer, M.; Pérez, G.; Tur, J.; Pons, A. LCitrulline-malate influence over branched chain amino acid utilization during exercise. Eur. J. Appl. Physiol. 2010, 110, 341-351.

(10) Osowska, S.; Duchemann, T.; Walrand, S.; Paillard, A.; Boirie, Y.; Cynober, L.; Moinard, C. Citrulline modulates muscle protein metabolism in old malnourished rats. Am. J. Physiol.: Endocrinol. Metab. 2006, 291, E582-E586.

(11) Jayaprakasha, G. K.; Chidambara, K. N.; Patil, B. S. Rapid HPLC-UV method for quantification of L-citrulline in watermelon and its potential role on smooth muscle relaxation. Food Chem. 2011, 127, 240-248.

(12) Pérez-Guisado, J.; Jakeman, P. M. Citrulline malate enhances athletic anaerobic performance and relieves muscle soreness. J. Strength Cond. Res. 2010, 24, 1215-1222.

(13) Goubel, F.; Vanhoutte, C.; Allaf, O.; Verleye, M.; Guillardin, J. M. Citrulline malate limits increase in muscle fatigue induced by bacterial endotoxins. Can. J. Physiol. Pharmacol. 1997, 75, 205-207.

(14) Boyer, J.; Brown, D.; Liu, R. H. Uptake of quercetin and quercetin 3-glucoside from whole onion and apple peel extracts by Caco-2 cell monolayers. J. Agric. Food Chem. 2004, 52, 7172-7179.

(15) Tarazona-Díaz, M.; Aguayo, E. Optimization of watermelon juice extraction: acidification, centrifugation, pasteurization and storage temperature. J. Sci. Food Agric. 2013, in press.

(16) Da Violante, G.; Zerrouk, N.; Richard, I. Short term Caco-2/ TC7 cell culture: comparison between conventional 21-d and a commercially available 3-d system. Biol. Pharm. Bull. 2004, 27, 19861992.

(17) Bahri, S.; Curis, E.; El Wafi, F. Z.; Aussel, C.; Chaumeil, J. C.; Cynober, L.; Zerrouk, N. Mechanisms and kinetics of citrulline uptake in a model of human intestinal epithelial cells. Clin. Nutr. 2008, 27, $872-880$.

(18) Artursson, P. Epithelial transport of drugs in cell culture. I: A model for studying the passive diffusion of drugs over intestinal absorptive (Caco 2) cells. J. Pharm. Sci. 1990, 79, 476-482.
(19) Norton, K.; Whittingham, N.; Carter, L.; Kerr, D.; Gore, C.; Marfell-Jones, M. Measurement techniques in anthropometry. In Anthropometrica, 1st ed.; Norton, K., Olds, T., Eds.; New South Publishing: Sydney, Australia, 1996; Vol. 1, pp 25-75.

(20) Mandel, H.; Levy, N.; Izkovitch, S.; Korman, S. H. Elevated plasma citrulline and arginine due to consumption of Citrullus vulgaris (watermelon). J. Inherit. Metab. Dis. 2005, 28, 467-72.

(21) Borg, G. Borg's Perceived Exertion and Pain Scales; Human Kinetics: Champaign, IL1998.

(22) Brown, J. R.; Collett, D.; Attwood, D.; Ley, R. W.; Sims, E. E. Influence of monocaprin on the permeability of a diacidic drug BTA243 across Caco- 2 cell monolayers and everted gut sacs. Int. J. Pharm. 2002, 245, 133-142.

(23) Lentz, K. A.; Hayashi, J.; Lucisano, L. J.; Poli, J. E.. Development of a more rapid, reduced serum culture system for Caco-2 monolayers and applications to the biopharmaceutics classification system. Int. J. Pharm. 2000, 200, 41-51.

(24) Yamashita, S.; Konishi, K.; Yamasaki, Y.; Taki, Y.; Sakane, T.; Sezaki, H.; Furuyama, Y. New and better protocols for a short-term Caco-2 cell culture system. Int. Pharm. Sci. 2002, 91, 669-679.

(25) Bravo, S. A.; Nielsen, C. U.; Amstrup, J.; Frokjaer, S.; Brodin, B. In-depth evaluation of Gly-Sar transport parameters as a function of culture time in the Caco-2 cell model. Eur. J. Pharm. Sci 2004, 21, 7786.

(26) Aherne, S. A.; Daly, T.; Jiwan, M. A.; O’sullivan, L.; O’Brien, N. Bioavailability on $\beta$-carotene isomer from raw and cooked carrots using an in vitro digestion model coupled with a human intestinal Caco-2 cell model. Food Res. Int. 2010, 43, 1449-1454.

(27) Cilla, A.; Alegría, A.; de Ancos, B.; Sánchez-Moreno, C.; Cano, M. P.; Plaza, L.; Clemente, G.; Lagarda, M. J.; Barbera, R. Bioaccessibility of tocopherols, carotenoids, and ascorbic acid from milk- and soy-based fruit beverages: influence of food matrix and processing. J. Agric. Food Chem. 2012, 60, 7282-7290.

(28) Rutherfurd, S. M.; Moughan, P. J.; van Osch, L. Digestible reactive lysine in processed feedstuffs: application of a new bioassay. $J$. Agric. Food Chem. 1997, 45, 1189-1194.

(29) Erbersdobler, H. F.; Hupe, A. Determination of lysine damage and calculation of lysine bio-availability in several processed foods. $Z$. Ernaehrungswiss. 1991, 30, 46-49.

(30) van Barneveld, R. J.; Batterham, E. S.; Norton, B. W. The effect of heat on amino acids for growing pigs. 3 . The availability of lysine from heat-treated field peas (Pisum sativum cultivar Dundale) determined using the slope-ratio assay. Br. J. Nutr. 1994, 72, 257-275.

(31) Pico, F. S.; Gutiérrez, D.; Arágon, G. I.; Escobar, S. A.; Ortíz, D.; Sánchez, T.; Imbachí, N. P.; Pachón, H. Evaluación de la composición nutricional, antinutricional y biodisponibilidad in vitro de diferentes extractos foliares. Rev. Chil. Nutr. 2011, 38, 168-176.

(32) Reboul, E.; Richelle, M.; Perrot, E.; Desmoulins-Malezet, C.; Pirisi, V.; Borel, P. Bioaccessibility of carotenoids and vitamin E from their main dietary sources. J. Agric. Food Chem. 2006, 54, 8749-8755.

(33) Jeffery, J. L.; Turner, N. D.; King, S. R. Carotenoid bioaccessibility from nine raw carotenoid-storing fruits and vegetables using an in vitro model. J. Sci. Food Agric. 2012, 92, 2603-2610.

(34) Han, H. K.; Vrueh, R. L.; Rhie, J. K.; Covitz, K. M.; Smith, P. L; Lee, C. P.; Oh, D. M.; Sadée, W.; Amidon, G. L. 5'-AA esters of antiviral nucleosides acyclovir and AZT are absorbed by the intestinal PEPT1 peptide transporter. Pharm. Res. 1998, 15, 1154-1159.

(35) Lucía, A.; Hoyos, J.; Chicharro, J. L. Preferred pedaling cadence in professional cycling. Med. Sci. Sport Exer. 2001, 33, 1361-1366.

(36) Takaishi, T.; Yasuda, Y.; Ono, T.; Moritani, T. Optimal pedaling rate estimated from neuromuscular fatigue for cyclists. Med. Sci. Sport Exer. 1996, 28, 1492-1497.

(37) Marsh, A.; Martin, P. E. Effect of cycling experience, aerobic power, and power output on preferred and most economical cycling cadences. Med. Sci. Sport Exer. 1997, 29, 1225-1232.

(38) Callis, A.; Magnan de Bornier, B.; Serrano, J. J.; Bellet, H.; Saumade, R. Activity of citrulline malate on acid-base balance and blood ammonia and amino acid levels. Study in the animal and in man. Arzneim.-Forsch. 1991, 41, 660-663. 
(39) Bendahan, D.; Mattei, J. P.; Ghattas, B.; Confort-Gouny, S.; Le Guern, M. E.; Cozzone, P. J. Citrulline malate promotes aerobic energy production in human exercising muscle. Br. J. Sport Med. 2002, $36,282-289$.

(40) Takeda, K.; Machida, M.; Kohara, A.; Omi, N.; Takemasa, T. Effects of citrulline supplementation on fatigue and exercise performance in mice. J. Nutr. Sci. Vitaminol. 2011, 57, 246-250.

(41) Gollnick, P. D.; Bayly, W. M.; Hodgson, D. R. Exercise intensity, training, diet, and lactate concentration in muscle and blood. Med. Sci. Sport Exer. 1986, 18, 334-340.

(42) Leicht, A. S.; Sealey, R. M.; Sinclair, W. H. Influence of cycle ergometer type and sex on assessment of 30-second anaerobic capacity and power. Int. J. Sports Med. 2011, 32, 688-692.

(43) Bethany, C. Evaluation of Lactate Concentration from 30 Seconds Wingate Test Using Three Sample Sites; Theses, Dissertations and Capstones, 2011; http://mds.marshall.edu/etd/46 (accesssed Oct 24, 2012).

(44) Lagally, M. K.; Robertsson, R. J.; Gallagher, K. I.; Goss, F. L.; Jakicic, J. M.; Lephart, S. M.; Mccaw, S. T.; Goodpaster, B. Percieved exertion, electromyography, and blood lactate during acute bouts of resistance exercise. Med. Sci. Sport Exer. 2001, 34, 552-559.

(45) Comeau, M.; Lawson, P.; Graves, M.; Church, J.; Adams, T. Visualization of the passive sink phenomenon in nonexercising muscle using 2 sampling sites: consequences for assessment and training. J. Strength Cond. Res. 2011, 25, 2926-2930.

(46) Cairns, S. P. Lactic acid and exercise performance: culprit or friend? Sports Med. 2006, 36, 279-291.

(47) Giannesini, B.; Le Fur, Y.; Cozzone, P. J.; Verleye, M.; Le Guern, M. E.; Bendahan, D. Citrulline malate supplementation increases muscle efficiency in rat skeletal muscle. Eur. J. Pharmacol. 2011, 667, 100-104. 